\title{
Nursing Care to Meet Fluid and Electrolyte Needs of Chronic Kidney Disease Patient
}

\author{
Tasya Shafa Rahman ${ }^{1}$, Sri Utami Dwiningsih ${ }^{2}$, Nina Indriyawati ${ }^{2}$ \\ ${ }^{1}$ Program Studi Diploma III Keperawatan Semarang \\ ${ }^{2}$ Jurusan Keperawatan Semarang \\ Corresponding author: tasyashafar@gmail.com
}

\begin{abstract}
Background: Chronic Kidney Failure (CKD) is a kidney function disorder that occurs gradually, cannot be recovered, and describes a decrease in urine production which results in an accumulation of fluid in the body. This can disrupt their fluid and electrolyte balance. In this regard, in Indonesia there are still many phenomena of noncompliance with fluid monitoring that occur. If this is left unchecked, it will result in a condition of overload or excess fluid in the patient. Fluid management is needed to fulfill the patient's fluid and electrolyte needs, so that changes in body weight and the results of the calculation of fluid balance can be controlled and become an illustration of meeting these needs.
\end{abstract}

Purpose: to explain nursing care to meet fluid and electrolyte needs in chronic kidney disease patients.

Methods: nursing care was carried out on patients with a diagnosis of chronic kidney disease who have impaired fluid and electrolyte requirements. The nursing intervention used to overcome this problem was fluid management. Data were collected from interviews and observations and further analysis was carried out.

Results: After three days nursing intervention, the results showed that the client's level of shortness of breath decreased, the blood pressure level was close to normal, fluid calculation close to balance, and the client's weight seemed stable.

Conclusion: fluid management was effective for monitoring fluid intake and output of chronic kidney disease patient.

Keywords:

CKD; fluid balance; weight monitor; hemodialysis, Cronic Kidney Diseasease.

\section{LATAR BELAKANG}

Chronic Kidney Diseases (CKD) atau dikenal dengan sebutan Gagal Ginjal Kronik (GGK) merupakan gangguan fungsi ginjal yang terjadi secara bertahap dan tidak dapat pulih kembali (Smeltzer \& Bare, 2002). Pada fungsi ginjal yang sehat, terjadi penyaringan sekitar 120-150 liter darah yang kemudian menghasilkan sekitar 1-2 liter urin di setiap harinya. Jika ia mengalami GGK, maka, produksi urin yang dikeluarkan akan berkurang dari semestinya, sehingga memicu terjadinya penumpukkan cairan di dalam tubuh (Faruq, 2017) Kemudian, apabila penumpukkan cairan tersebut tidak dapat 
ditangani dengan tepat, maka, terjadilah edema pada seluruh atau sebagian tubuh pasien. Kondisi pada pasien GGK itulah yang menandakan bahwa tubuhnya telah kehilangan kemampuan untuk mempertahankan volume serta komposisi cairan dan elektrolit (Smeltzer, Bare, Hinkle, Cheever \& Towsend, 2010).

Gangguan keseimbangan cairan dan elektrolit dapat disebabkan oleh ketidakefektifan cairan yang masuk ataupun keluar dari dalam tubuh. Jika hal tersebut tidak ditangani dengan tepat, maka pasien gagal ginjal kronik akan mengalami kondisi overload atau kelebihan cairan. (Angraini \& putri, 2016). Keadaan tersebut dapat dilihat melalui beberapa tindakan keperawatan yang meliputi, pemantauan TTV (TD), status mental, CVP, distensi vena leher, suara nafas, berat badan, status hidrasi, pemantauan adanya edema, ascites, dan evaluasi berdasarkan kolaborasi pembatasan cairan serta pemantauan intake output, sebelumnya (Dongoes, Moorhouse, \& Murr, 2010).

Menurut hasil univariat dalam penelitian Meilianna dan Wiarsih tahun 2019, menunjukkan bahwa pembatasan cairan yang efektif dapat dilihat dengan adanya kepatuhan dari responden tersebut. Kemudian, telah tercatat pada akhir oktober 2003 terdapat 441.051 pasien GGK yang 66\% diantaranya mengalami perawatan terapi hemodialisis dan beresiko terhadap overload cairan (US Renal Data System dalam Priska \& Herlina, 2019), kemudian 76\% dari 84 responden merupakan pravelansi pasien GGK yang mengalami ketidakpatuhan dalam pembatasan cairan (Meilianna \& Wiarsih, 2019), serta $10 \%$ sampai $60 \%$ diantaranya juga menunjukkan adanya kesuksesan hemodialisis terhadap kepatuhan pembatasan cairan (Rustiawati, 2012), dan ditambahkan pula pravelansi 53,6\% dari keseluruhan responden yang diteliti oleh Meilianna \& Wirasih (2019) dimana penyakit gagal ginjal kronik tersebut masih mengalami overload cairan. Tak hanya itu, pada 15 Maret 2021, saat peneliti melakukan studi pendahuluan sekaligus praktik klinik keperawatan medikal bedah II di RSUD Bendan, Kota Pekalongan, didapatkan sebuah informasi berdasarkan wawancara sederhana, yakni terdapat 3 pasien gagal ginjal kronik yang dirawat dengan masalah kelebihan volume cairan. 1 pasien diantaranya cukup kooperatif dalam berkomunikasi, 1 pasien lainnya rawat jalan dan sisanya dalam kondisi buruk hingga dilarikan ke ruang ICU.

Overload cairan yang dialami oleh pasien GGK dapat dibuktikan dengan adanya peningkatan berat badan yang melebihi berat badan normal, yakni meningkat $0,5 \mathrm{~kg}$ dalam 24 jam (Priska dan Herlina, 2019). Menindaklanjuti hal tersebut, manajemen cairan yang dapat dilakukan selain adanya pembatasan cairan, yakni dilakukannya pemantauan Intradialytic Weight Gain (Priska dan Herlina, 2019). IDWG (Intradialytic Weight Gain) digunakan oleh peneliti guna mengevaluasi sejauh mana pasien tersebut dapat mengatur intake cairan, yang kemudian di kalkulasi dalam kilogram atau sebagai presentasi berat badan kering pasien. Hal tersebut dilakukan guna menurunkan resiko overload diantara waktu dialisis, yang dimana seharusnya BB pasien kurang dari 2,5 kg atau 5\% dari berat badan diantara dua sesi dialisis tersebut (Sharaf, 2016).

Berdasarkan pemaparan diatas, penulis semakin tertarik akan pengambilan kasus tersebut, dikarenakan, hampir separuh dari pravelansi penyakit gagal ginjal masih mengalami adanya overload cairan. Sehingga, penulis semakin tertarik akan memecahkan kasus pemenuhan kebutuhan cairan dan elektrolit pada pasien GGK 
dengan intervensi yang dirasa tetap efektif dalam waktu pemberian asuhan 3 x 24 jam. Kemudian, penulis lebih menekankan pada pola pembatasan cairan serta pemantauan BB pasien sebagai penyelesaian kasus dengan didukung tindakan keperawatan lainnya guna memantau terpenuhinya kebutuhan cairan dan elektrolit tersebut.

\section{TUJUAN}

Menggambarkan asuhan keperawatan pemenuhan kebutuhan cairan dan elektrolit pada pasien gagal ginjal kronik.

\section{METODE}

Penelitian ini menggunakan desain studi kasus dengan pendekatan asuhan keperawatan yakni penelitian dengan cara mengumpulkan data yang dimulai dari pengkajian, menentukan diagnosis, menyusun perencanaan, melaksanakan tindakan keperawatan, dan melakukan evaluasi yang diberikan pada satu orang pasien gagal ginjal kronik dengan masalah gangguan pemenuhan kebutuhan cairan dan elektrolit selama 3x24 jam. Tidak ada pembatasan usia dan tidak menentukan jenis kelamin yang akan dijadikan responden dalam studi kasus. Teknik pengumpulan data dengan menggunakan teknik wawancara terstruktur dan observasi. Analisa data dilakukan sejak peneliti melakukan asuhan keperawatan yang dimulai dari pengkajian hingga pendokumentasian pada setiap harinya guna mengetahui perkembangan dari pasien tersebut.

\section{HASIL}

Seorang klien bernama Ny. S berusia 70 tahun, bekerja sebagai ibu rumah tangga, dan berstatus menikah ini tinggal di Kandang Panjang, Pekalongan. Beliau terdiagnosa medis CKD on HD atau disebut gagal ginjal kronik dengan terapi rutin hemodialisa 2 kali dalam seminggu. Ny. S hanya lulusan SD yang diantar anaknya masuk ke RS pada tanggal 15 Maret 2021. Setelah dari IGD, klien mendapatkan nomor RM yakni 00010xxx. Klien kemudian dipindahkan ke ruang jlamprang pada pukul 19.00 WIB dan mulai dikaji oleh peneliti pada tanggal 16 Maret 2021.

Pada saat dilakukan pengkajian, Ny. S mengatakan bahwa dirinya merasa lemas, mudah kelelahan, dan kesulitan bernafas saat dalam kondisi berbaring terlentang. Sesak nafas yang dirasakan klien tersebut menjadi keluhan utama klien saat pertama kali dilakukan pengkajian dan alasan keluarga membawa Ny.S ke Rumah Sakit. Kemudian, klien mengatakan bahwa beliau dalam 2 kali seminggu melakukan pemeriksaan berkala dan terapi hemodialisis. Klien mengatakan bahwa ia telah mengalami penyakit gagal ginjal kronik ini sejak 5 tahun yang lalu akibat dari lifestyle atau pola hidup yang kurang baik, klien bercerita bahwa semasa mudanya sering kali meninggalkan air putih. Keluarga klien juga mengatakan bahwa anggota keluarga lainnya tidak mempunyai riwayat penyakit yang sama seperti klien. Namun, terdapat riwayat penyakit keluarga sebelumnya, yakni ibu dari klien yang sempat mengalami diabetes milletus.

Klien juga tidak menolak akan dirinya yang mengalami penyakit gagal ginjal tersebut. Klien mengatakan bahwa ia bersyukur pada Tuhan, bahwasannya masih diberi kesempatan hidup meski harus dengan cuci darah secara rutin. Klien juga mengatakan bahwa penyakitnya ini tidak begitu mempengaruhi perannya di masyarakat, sebab ia masuk ke dalam kelompok lansia, sehingga aktivitas di dalam kelompok masyarakatnya tidak begitu banyak. 
Dalam pola pengkajian Gordon, didapatkan pernyataan dari keluarga klien bahwasannya dalam manajemen kesehatannya, keluarga mengatakan pada saat klien mengeluh sakit tetapi terasa ringan, maka keluarga klien akan memberikan obat dari apotek atau membawanya ke klinik terdekat. Namun, semenjak klien terdiagnosa penyakit kronik dan memerlukan perawatan yang lebih intensif, maka keluarga klien lebih mengutamakan datang ke RSUD daripada mencari klinik terdekat. Selama di rumah sakit klien mengatakan selera makannya sedikit menurun dibandingkan pada saat ia berada di rumah. Meski begitu, klien mengatakan bahwa ia berusaha menghabiskan porsi makan yang telah diperhitungkan oleh rumah sakit. Secara nutrisi, klien terpenuhi namun pada status cairannya, kebutuhan klien tidak terpenuhi dikarenakan hasil perhitungan balance cairannya selalu positif atau lebih dari kebutuhannya.

Ny. S cukup patuh pada aturan yang diberikan tenaga kesehatan untuk kebaikan dirinya. Pola eliminasi klien sedikit terganggu, dimana klien hanya buang air kecil 1-2 kali sehari. Klien mengatakan lebih suka menggunakan pampers dewasa daripada menggunakan kateter. Sehingga, peneliti mengukur urin yang ditampung berdasarkan berat pampers penuh dikurangi dengan berat pampers bersih, sehingga di dapatkan berat urin pada pampers tersebut. Pada saat pengkajian awal, urin klien sebanyak $100 \mathrm{cc}$ dalam sehari dan klien mengeluh belum BAB sejak kemarin.

Pada pemeriksaan fisik klien, didapatkan data suhu Ny. S yakni 36 derajat celcius, nadi 80x/menit, frekuensi nafas 20x/menit, tekanan darah 130/100mmHg. Kesadaran klien composmentis dengan hasil GCS E4 V5 M6 dan dalam keadaan umum sedang. Selain itu, klien mengeluh sesak nafas jika berbaring terlentang (ortopnea), kemudian bentuk dada klien simetris dengan pola nafas sedikit berantakan terutama saat klien dalam posisi berbaring. Kulit klien dan mukosa bibir kering, turgor kulit kurang elastis. Klien tidak terpasang NGT, dan berat badan awal pengkajian yakni $47 \mathrm{Kg}$. Klien juga merasa bengkak pada ekstremitas atas sebelah kiri dengan pitting edema lebih dari 3 detik juga terasa adanya nyeri tekan akibat dari pemasangan infus yang kurang tepat sebelum klien dipindahkan ke ruangan. Oleh sebab itu, infus klien kemudian dipindahkan ke tangan sebelah kanan.

Pada pemeriksaan penunjang, didapatkan hasil laboratorium pada 16 Maret 2021 bahwa hemoglobin klien $10.6 \mathrm{gr} / \mathrm{dL}$ dan hematokritnya $30.7 \%$. Klien mendapatkan program terapi infus RL 7 tpm untuk 500 cc per-hari, injeksi furosemide 20mg untuk mengatasi tekanan darah klien yang tinggi sehingga mencegah edema anasarka terjadi dan injeksi ketorolac 10mg x 1 dikarenakan klien mengeluhkan rasa nyeri. Pada perhitungan balance cairan, hari pertama awal pengkajian, Ny. S mengalami kelebihan cairan sebanyak 52 cc dalam sehari. 
Tabel 1. Balance cairan pengkajian awal

\begin{tabular}{lc}
\hline Variabel & Input Cairan \\
\hline Cairan Infus & $600 \mathrm{cc}$ \\
Obat Injeksi & $2 \mathrm{cc}$ \\
Asupan Makan & $180 \mathrm{cc}$ \\
Minum & $75 \mathrm{cc}$ \\
Total & $857 \mathrm{cc}$ \\
& Output Cairan \\
Urine & $100 \mathrm{cc}$ \\
IWL & $705 \mathrm{cc}$ \\
Total & $805 \mathrm{cc}$ \\
Balance Cairan : Input - Output & $857-805=(+) \mathbf{5 2} \mathbf{~ c c}$
\end{tabular}

Berdasarkan data pengkajian klien sebelumnya, peneliti mampu mendapatkan beberapa data fokus yang dikelompokkan sebagai berikut :

Secara subjektif didapatkan data yakni :

a. Klien mengatakan bahwa ia merasa mudah kelelahan

b. Klien mengeluh BAKnya lebih sedikit dari sebelumnya

c. Klien mengeluh kesulitan bernafas pada saat berbaring

Secara objektif didapatkan data yakni :

a. Frekuensi nafas klien 20x/menit dimana termasuk tadipnea pada lansia

b. Denyut nadi klien $80 x /$ menit termasuk tinggi pada golongan usianya

c. Intensitas BAK klien tampak hanya 1 kali penggantian pampers dalam sehari (sehingga intensitas menurun)

d. Tekanan darah klien tinggi yakni, 130/100mmHg

e. Adanya pembesaran kandung kemih klien

f. Turgor kulit klien kurang elastis

g. Kulit klien nampak kering

h. Terdapat data balance cairan yang kelebihan, dimana klien mengalami kelebihan cairan sebanyak 52 cc dalam sehari.

i. Hasil laboratorium $\mathrm{Hb} 10.6 \mathrm{gr} / \mathrm{dL}$ dan $\mathrm{Ht} 30.7 \%$ masuk dalam kategori rendah

Sehingga, berdasarkan data fokus tersebut, sesuai dengan tanda gejala mayor maupun minor pada SDKI menghasilkan diagnosa keperawatan yakni, Hypervolemia (kelebihan volume cairan) berhubungan dengan gangguan mekanisme regulasi.

Masalah keperawatan tersebut akan diselesaikan dengan perencaaan menurut SIKI yang memiliki kriteria hasil berdasarkan SLKI yakni, diharapkan setelah dilakukannya intervensi selama 3x24 jam, klien mampu terpenuhi kebutuhan cairan dan elektrolitnya dengan didapatkannya perbaikan pada keseimbangan cairannya (L.03020). Dengan begitu, agar tujuan tersebut dapat berhasil, peneliti mengajukan beberapa pelaksaan intervensi menurut SIKI yakni, dilakukannya manajemen hypervolemia (L.03114) dimana terdapat langkah-langkah sebagai berikut :

a. Periksa tanda dan gejala hypervolemia

b. Monitor status tekanan darah klien

c. Monitor intake dan output cairan klien

d. Monitor kecepatan infus klien 
e. Monitor efek samping pemberian diuretic pada klien

f. Lakukan penimbangan berat badan setiap hari

g. Tinggikan kaki klien di tempat tidur sekitar 30-40 derajat celcius guna mencegah edema perifer

h. Kolaborasi pemberian diuretic untuk klien

Selain itu, terdapat pula intervensi lainnya, seperti pemantauan cairan menurut SIKI dengan kode L.02121 yang berisi langkah sebagi berikut :

a. Monitor frekuensi dan kekuatan nadi

b. Monitor frekuensi nafas klien

c. Monitor tekanan darah klien

d. Monitor berat badan klien

e. Monitor elastisitas atau turgor kulit

f. Monitor jumlah urin yang keluar dan dokumentasikan hasil pemantauan

g. Berikan edukasi singkat mengenai tujuan dan manfaat pemantauan cairan pada klien dan informasikan hasil tersebut jika diperlukan

Implementasi asuhan keperawatan Ny. S dilakukan mulai pada tanggal 16 Maret 2021 hingga 18 Maret 2021 dengan beberapa tindakan pengelolaan seperti melakukan bina saling percaya, memonitor intake dan output cairan klien setiap harinya, memonitor tanda vital klien, mengamati keadaan integumen klien, membantu meninggikan tempat tidur menjadi posisi semifowler guna mengurangi sesak saat berbaring, meninggikan kaki klien dengan bantal selama 15 menit guna pencegahan terjadinya edema perifer. Pada tanggal 17 Maret 2021, klien dijadwalkan untuk hemodialisa sehingga pengukuran berat badannya dilakukan pada saat sebelum dan sesudah hemodialisa. Klien juga mendapatkan 2 jenis terapi injeksi $1 \times 24$ jam pada hari pertama yakni injeksi ketorolac dan diuretic (furosemide). Pemantauan cairan klien dibantu oleh keluarga klien serta kerabat praktikan yang dimintai bantuan oleh peneliti agar monitoring tetap terlaksana meski peneliti hanya mampu bertemu klien dalam shift/jam kerja saja. Pada akhir pelaksanaan implementasi, peneliti merapikan catatan balance cairan klien dan dihitungnya sesuai dengan ketentuan yang berlaku dan didapatkan hasil evaluasi sebagai berikut:

Tabel 2. Perbandingan hasil monitoring sebelum dan sesudah implementasi

\begin{tabular}{|c|c|c|c|}
\hline \multirow[b]{2}{*}{ Hasil Monitoring } & \multirow{2}{*}{$\begin{array}{l}\text { Sebelum Intervensi } \\
16 \text { Maret } 2021\end{array}$} & \multicolumn{2}{|c|}{ Setelah dilakukan intervensi } \\
\hline & & 17 Maret 2021 & 18 Maret 2021 \\
\hline Tekanan Darah & $130 / 100 \mathrm{mmHg}$ & $130 / 90 \mathrm{mmHg}$ & $130 / 88 \mathrm{mmHg}$ \\
\hline $\begin{array}{l}\text { Hasil Balance } \\
\text { Cairan }\end{array}$ & (+) $52 \mathrm{cc}$ & (+) $40 \mathrm{cc}$ & (+) $35 \mathrm{cc}$ \\
\hline Frekuensi Nafas & 20x/menit & $18 \mathrm{x} / \mathrm{menit}$ & $16 \mathrm{x} / \mathrm{menit}$ \\
\hline Frekuensi Nadi & $80 x / m e n i t$ & $78 \mathrm{x} / \mathrm{menit}$ & $70 x /$ menit \\
\hline Integumen & Kering & Kering & Sedang \\
\hline Hasil Monitoring & Sebelum Intervensi & Setelah dilakuk & vensi \\
\hline
\end{tabular}


Jendela Nursing Journal, 5(1), 2021,

16 Maret 2021

17 Maret 2021

18 Maret 2021

Berat Badan

$47 \mathrm{Kg}$

Pre HD : $49 \mathrm{~kg}$

Post HD : 47kg

$47 \mathrm{~kg}$

Hasil laboratorium :

Hemoglobin

$10.6 \mathrm{gr} / \mathrm{dL}$

$11.3 \mathrm{gr} / \mathrm{dL}$

Hematokrit

$30.7 \%$

$34.5 \%$

Selain evaluasi dari tabel 2 diatas, secara subjektif klien mengatakan bahwa rasa lemasnya berangsur-angsur kurang, serta perasaan sesak saat beliau berbaring juga berkurang. Dengan begitu, masalah pada Ny. S dapat teratasi sebagian dengan planning/rencana tindak lanjut yakni melanjutkan intervasi pada pemantauan cairan klien agar mendekati yang kondisi stabil.

Tabel 3. Perhitungan balance cairan klien

\begin{tabular}{|c|c|c|}
\hline Hari (BB) & Variabel & Hasil \\
\hline & Input Cairan & \\
\hline & Cairan Infus & $600 \mathrm{cc}$ \\
\hline & Obat Injeksi & $2 \mathrm{cc}$ \\
\hline & Asupan Makan & $180 \mathrm{cc}$ \\
\hline & Minum & $75 \mathrm{cc}$ \\
\hline \multirow{6}{*}{$\begin{array}{c}\text { Hari ke } 1 \\
(\mathrm{BB}: 47 \\
\mathrm{kg})\end{array}$} & Total & $857 \mathrm{cc}$ \\
\hline & Output Cairan & \\
\hline & Urine & $100 \mathrm{cc}$ \\
\hline & IWL & $705 \mathrm{cc}$ \\
\hline & Total & $805 \mathrm{cc}$ \\
\hline & Balance Cairan : Input-Output & $857-805=(+) 52 \mathrm{cc}$ \\
\hline \multirow[t]{2}{*}{ Hari ke 2} & Input Cairan & \\
\hline & Cairan Infus & $700 \mathrm{cc}$ \\
\hline (BB pre & Cairan injeksi & - \\
\hline HD : 49 & Asupan Makanan & $120 \mathrm{cc}$ \\
\hline kg dan & Minum & $125 \mathrm{cc}$ \\
\hline $\mathrm{BB}$ post & Total & $945 \mathrm{cc}$ \\
\hline \multirow{5}{*}{$\begin{array}{l}\text { HD pada } \\
\text { pukul } \\
19.00: 47 \\
\mathrm{~kg} \text { ) }\end{array}$} & Output Cairan & \\
\hline & Urine & $200 \mathrm{cc}$ \\
\hline & IWL & $705 \mathrm{cc}$ \\
\hline & Total & $905 \mathrm{cc}$ \\
\hline & Balance Cairan : Input-Output & $945-905=(+) 40 \mathrm{cc}$ \\
\hline
\end{tabular}


Jendela Nursing Journal, 5(1), 2021,

\begin{tabular}{cll}
\cline { 2 - 3 } Hari & Variabel & Hasil \\
\cline { 2 - 3 } & Input Cairan & \\
& Cairan Infus & $550 \mathrm{cc}$ \\
& Obat Injeksi & - \\
& Asupan makan & $165 \mathrm{cc}$ \\
& Minum & $125 \mathrm{cc}$ \\
& Total & $840 \mathrm{cc}$ \\
& Output Cairan & \\
Hari ke 3 & Urine & $100 \mathrm{cc}$ \\
(BB : 47 & IWL & $705 \mathrm{cc}$ \\
$\mathrm{kg})$ & Total & $805 \mathrm{cc}$ \\
& Balance Cairan : Input - Output & $840-805=(+) 35 \mathrm{cc}$
\end{tabular}

\section{PEMBAHASAN}

Tahap pengkajian, klien mengeluh mudah lelah dengan hasil pemeriksaan laboratorium pada hemoglobin $10.6 \mathrm{gr} / \mathrm{dL}$ dimana nilai tersebut dibawah rentang normal yakni 11.7 $15.5 \mathrm{gr} / \mathrm{dL}$ dan hematokrit klien $30.7 \%$ dimana nilai tersebut berada dibawah rentang normalnya, yakni 35-47 \%. Hal ini rupanya tengah menjadi gejala yang biasa ditimbulkan oleh klien dengan gagal ginjal kronik. Menurut Sullivan (2009), jika klien telah lama menjalani terapi hemodialisa maka akan cenderung memiliki kadar ureum dan kreatinin yang tinggi, sehingga dapat mengganggu produksi pada eritropoietinnya. Jika eritropoietinnya terganggu maka, jumlah sel darah merah akan menurun (anemia) dan mengakibatkan timbulnya gejala lelah, letih lesu yang kemudian dikenal dengan fatigue atau kelelahan. Selain itu, nilai hematokrit umumnya normal, akan tetapi bila terjadi penurunan maka dapat diindikasikan bahwa klien tersebut mengalami kelebihan cairan yang bersifat akut. Berdasarkan teori tersebut, peneliti sangat menyayangkan kurangnya data $\mathrm{Ny}$. S untuk pemantauan kadar ureum dan kreatininnya, namun, dapat dialternatifkan dengan penggambaran hasil laboratoriumnya yang dimana, jika hemoglobin dan hematokritnya turun maka secara tidak langsung menggambarkan pula kondisi ureum dan kreatinin pada klien sedang tinggi.

Data eliminasi urin klien pada hari pertama sebanyak $100 \mathrm{cc}$, pada hari kedua sebanyak $200 \mathrm{cc}$ dan hari ketiga haluaran urin klien sebanyak $100 \mathrm{cc}$. Hal ini mengindikasikan bahwa terjadi penurunan produksi urin sehingga $\mathrm{Ny}$. S mengalami oliguria, yakni kondisi dimana klien buang air kecilnya lebih sedikit dari biasanya. Kondisi tersebut terjadi akibat penurunan fungsi ginjal sehingga retensi natrium dan cairan akan mengakibatkan organ ginjal itu sendiri tidak mampu dalam mengkonsentrasikan atau mengencerkan urine secara normal (Smetzer \& Bare, 2013 dalam Sari, 2016). Selain itu, retensi urin yang klien alami termasuk dalam retensi urin akut, yang dimana penderita tersebut seakan-akan tidak dapat berkemih (miksi), namun, sering kali urin tersebut keluar atau menetes sedikit demi sedikit (Mansjoer et al., 2000). Menurut teori dalam SDKI, oliguria juga masuk ke salah satu tanda dan gejala minor secara objektif pada diagnosa kelebihan volume cairan.

Berdasarkan data pengkajian berikutnya, terdapat masalah pada sistem respirasi klien, dimana klien mengeluh sesak nafas ketika berbaring atau disebut dengan ortopnea. Di 
dukung pula dengan frekuensi pernafasan klien yakni 20x/menit yang dimana termasuk dalam frekuensi cepat menurut usianya. Ny. S termasuk ke dalam kategori lansia, sebab usianya sudah menginjak 70 tahun, sehingga dalam slideshare Tri Kusniati (2017) menyatakan bahwa frekuensi nafas normal pada lansia yakni berkisar 14-16x/menit. Menurut SDKI, tanda dan gejala mayor pada klien dengan masalah kelebihan volume cairan, salah satunya terdapat data subjektif yakni ortopnea dan/atau dipsnea. Sehingga, data yang ada pada Ny. S selaras dengan teori tersebut. Ditambahkan pula dengan teori milik Satria (2017), yang mengatakan bahwa sesak nafas juga dapat terjadi akibat peningkatan kreatinin dalam darah sehingga menyebabkan ketidakmampuan darah dalam mengantarkan oksgien dengan baik. Kondisi gangguan pada darah inilah yang akan menyebabkan tubuh menjadi kekurangan oksigen, sehingga tubuh akan mengkompensasi dengan cara bernafas lebih cepat seperti halnya orang yang sesak.

Pada sistem kardiovasikulernya, klien mengalami tekanan darah yang cukup tinggi yakni 130/100mmHg. Nilai normal tekanan darah sesuai dengan usia klien yakni, diantara 130-150/80-90mmHg. Kemudian, frekuensi nadi klien 80x/menit yang dimana termasuk lebih cepat dari normalnya, sebab normal pada kelompok usia klien yakni 6070x/menit. Peningkatan tekanan darah systole maupun diastole akibat gagal ginjal kronik dikarenakan terjadinya penurunan aliran darah ke ginjal serta laju filtrasi glomerulus (LFG) yang berkurang sehingga meningkatkan sistem Renin Angiotensin Aldosteron (RAA).

Sel apartus jukstaglomerulus mensekresi enzim renin yang dapat merubah angiotensinogen yang berasal dari hati menjadi angiotensin I kemudian diubah menjadi Angiotensin II oleh Angiotensin Converting Enzyme (ACE). Angiotensin II dapat menyebabkan vasokontriksi pembuluh darah tepi dan menyebabkan peningkatan tekanan darah (Cianci et al, 2009) selain itu, Angiotensin II juga merangsang aldosterone yang dapat meningkatkan retensi air dan natrium $(\mathrm{Na})$ di tubulus ginjal dan menyebabkan tekanan darah meningkat sehingga terjadi pula hypervolemia akibat peningkatan reabsorbsi natrium di ductus koligentes karena adanya resistensi relative terhadap hormone natriuetik peptida dan peningkatan aktivitas pompa yang mengakibatkan curah jantung meningkat sehingga menyebabkan tekanan darah meningkat. Perlu diperhatikan bahwa peningkatan aktivitas aldosterone tersebut jika dibiarkan dapat memperberat hypervolemia yang terjadi (Cianci et al, 2009).

Pada sistem dermatologi klien, didapatkan data pengkajian dimana kulit klien tampak dan terasa kering. Kekeringan kulit tersebut dapat terjadi karena uremia yang menyebabkan perubahan maturase korneosit (Harlim \& Yogyartono, 2012). Selain itu, keluhan klien berupa kondisi kulit yang kering merupakan manifestasi klinis dari keadaan uremia yang dialami oleh klien tersebut (Angraini \& Putri, 2016).

Pada perhitungan balance cairan, menurut hasil pada tabel 4.2. intake cairan klien berada dikisaran $800-900 \mathrm{cc} / 24 \mathrm{jam}$ sedangkan hasil perhitungan berat badan interdialisis klien mengalami presentase lebih dari 4\%, yakni 4,2\%. Dari data tersebut, klien semakin menjurus pada masalah kelebihan volume cairan. Hal ini didukung oleh hasil penelitian Lopez-Gomez (2005), menyatakan bahwa agar komplikasi pada penyakit gagal ginjal kronik dapat terkendalikan atau bahkan berkurang, maka berat badan interdialisis klien tidak boleh lebih dari 3,5\% - 4\% berat badan kering. Hasil 
peninjauan kasus tersebut menunjukkan bahwa intake cairan yang dikonsumsi klien paling tinggi yakni $945 \mathrm{cc} / 24$ jam di hari klien melakukan terapi hemodialisa.

Hal ini dikarenakan klien kurang memiliki pemahaman terhadap pentingnya pembatasan cairan. Seperti yang dikatakan Abuelo (1999), yakni, banyaknya cairan yang dikonsumsi oleh pasien kadang kala bukan karena rasa haus, akan tetapi hanya untuk membantu klien dalam menelan makanan atau obat-obatan. Meski begitu, faktanya, pasien yang menjalani hemodialisis jangka panjang masih sering mengalami gejala uremia dan kelebihan cairan yang dapat mengakibatkan hipertensi serta edema paru (Fisher, 2006) dan ditambahkan pula menurut Sapri (dalam Sitanggang, 2009) dimana kelebihan volume cairan tubuh cenderung dialami oleh klien penyakit gagal ginjal baik sebelum dan sesudah dilakukannya terapi hemodialisis. Pada klien hemodialisa rutin, fluktuasi atau kelebihan cairan tersebut disebabkan oleh penurunan fungsi ginjal dalam mengekresikan cairan dan kurangnya kepatuhan klien dalam membatasi asupan cairannya.

Diagnosa keperawatan merupakan suatu keputusan klinik yang diberikan kepada klien mengenai respon individu untuk menjaga penurunan kesehatan, status, dan mencegah serta merubahnya (Nanda I, 2018). Berkaitan dengan data hasil pengkajian, dapat ditegakan diagnosa pada klien $\mathrm{Ny}$. S yakni kelebihan volume cairan berhubungan dengan gangguan mekanisme regulasi. Diagnosa tersebut terdapat pada panduan SDKI dengan kode D.0022 Hipervolemia yang memiliki definisi peningkatan volume cairan intravascular, interstisial, dan/atau intraselular. Adapun penyebabnya yakni gangguan mekanisme regulasi, kelebihan asupan cairan, kelebihan asupan natrium, gangguan aliran balik vena dan efek agen farmakologis. Disertai pula gejala dan tanda mayor yang dapat terjadi seperti ortopnea, dispnea, paroxysmal nocturnal dyspnea (PND), edema anasarka/perifer, berat badan meningkat dalam waktu singkat, JVP meningkat, dan terdapat refleks hepatojugular positif. Selain itu, tanda dan gejala minor pada diagnosa tersebut, yakni, terdengar suara nafas tambahan, hepatomegali, kadar $\mathrm{Hb} / \mathrm{Ht}$ menurun, oliguria, intake lebih banyak dari output (balance cairan positif), dan kongesti paru. Hal ini didukung oleh penelitian Angraini dan Putri (2016), yang menyatakan bahwa klien dengan GGK berpotensi menimbulkan sebuah komplikasi yakni kondisi overload cairan/kelebihan volume cairan, dengan kata lain, Apriyaningsih (2016) menyatakan bahwa klien GGK harus dilakukan tindakan yang tepat sebab akan menyeb ${ }^{-} 58$ kelebihan volume cairan.

Terhadap diagnosa keperawatan klien, dilakukan tindakan keperawatan dan asuhan keperawatan yang sesuai dengan tinjuan pustaka. Peneliti merencanakan beberapa intervensi untuk klien dan dilakukan sesuai dengan keadaan serta kondisi terkini klien yang didapatkan pada saat pengkajian. Intervensi tersebut yakni monitor status tekanan darah klien, monitor intake output klien, monitor berat badan klien, monitor jumlah urin yang keluar, meninggikan kaki klien guna mencegah edema perifer, kolaborasi pemberian diuretic untuk klien, dan edukasi singkat mengenai tujuan dan manfaat pemantauan cairan pada klien. Hal ini dilakukan dengan tujuan untuk memenuhi kebutuhan cairan klien agar terhindar dari komplikasi overload cairan yang telah dialami. Intervensi yang telah ditetapkan bagi klien telah sesuai dengan teori menurut Tim Pokja DPP PPNI (2018) yaitu manajemen hipervolemia dan pemantauan cairan. 
Implementasi dilakukan sesuai dengan perencanaan keperawatan dan kondisi pasien selama pelaksanaan studi kasus, dengan diagnosa klien yakni kelebihan volume cairan berhubungan dengan gangguan mekanisme regulasi, peneliti melakukan beberapa intervensi terpilih seperti. Mengkaji tanda tanda vital klien dilakukan untuk mengetahui kondisi serta mengendalikan tekanan darah klien, karena tekanan darah yang tinggi akan lebih mudah mempercepat perkembangan kerusakan pada organ ginjal itu sendiri (Ariani, 2016 dalam Sari 2016). Hal ini di dukung pula oleh teori Black dan Hawk (2009 dalam Anggraini dan Putri 2016) yang menyatakan bahwa pemantauan tekanan darah merupakan salah satu indikator adanya peningkatan intravaskuler. Peningkatan volume cairan berlebih pada kompartemen intravaskuler lebih lanjut akan menyebabkan terjadinya perpindahan cairan dari pembuluh darah menuju jaringan intertisial tubuh. Oleh sebab itulah, pemantauan tekanan darah pada pasien gagal ginjal kronik sangat penting dilakukan guna memperkirakan terjadinya overload pada klien tersebut.

Penelitian Wang (2015 dalam Sari 2016) menyatakan penimbangan berat badan dilakukan setiap hari. Hal ini dikarenakan penambahan berat badan sangat berpengaruh terhadap keseimbangan cairan. Pada tabel 4.1 terjadi peningkatan berat badan dari hari pertama ke hari ke dua sebelum terapi hemodialisis atau diantara waktu dialisis. Penambahan berat badan antara dua waktu dialisis ini disebabkan oleh ketidakmampuan ginjal dalam menjalani fungsi eksresinya, sehingga berapapun jumlah cairan yang masuk dan dikonsumsi klien akan selalu ada penambahan dengan kata lain penambahan berat badan sebanyak nol ml tidak akan mungkin terjadi (Yosi S, 2010). Meski begitu, peningkatan berat badan klien memang terbilang melebihi batas normal, namun didukung oleh teori lain yang mengatakan bahwa peningkatan berat badan antara dua waktu dialisis yang melebihi 4,8\% akan meningkatkan mortalitas meskipun tidak digambarkan besarannya (Foley, Herzog \& Collins 2002 dalam Pace 2007). Dengan begitu, penambahan yang terjadi pada Ny. S masih tergolong cukup aman dan akan tetap dilakukan adanya pemantauan berat badan dikarenakan, penambahan berat badan yang dialami klien telah melebihi $0,2 \%$ dari batas normal.

Pemantauan status hidrasi pada pasien gagal ginjal kronik meliputi pemantauan intake dan output cairan selama 24 jam dengan menggunakan chart intake output yang kemudian dilakukan perhitungan balance cairan (balance positif menunjukkan keadaan overload cairan) (Anggraini \& Putri 2016). Indikasi efektivitas monitoring input dan output cairan yakni terjadinya penurunan terhadap status kelebihan atau nilai positif pada balance cairan tersebut. Untuk menghitung balance cairan tersebut menggunakan rumus input dikurangi output klien. Input cairan antara lain, makan/minum, cairan infus, dan injeksi. Sedangkan output cairan antara lain, IWL dengan rumus (15 x berat badan), feses, urin, muntah dan pendarahan (Ambarwati,2014).

Posisi semifowler merupakan suatu posisi dimana bagian kepala tempat tidur dinaikkan 30-45 derajat. Posisi ini menurut Aziz (2008) cukup efektif guna mempertahankan kenyamanan dan memfasilitasi fungsi pernafasan klien. Hal ini dilakukan oleh peneliti dikarenakan Ny. S mengeluhkan perihal merasa sesak pada saat berbaring. Menganjurkan pasien untuk melakukan aktivitas horizontal atau meninggikan kaki secara bergantian dan menghindari penyilangan kaki dikarenakan pernyataan pada penelitian Siregar (2010 dalam Setyaningrum 2016) yakni, bahwasannya peninggian posisi kaki 30 derajat di atas tempat tidur dapat mengurangi dan atau menurunkan 
resiko edema pada kaki. Peninggian ini melawan tarikan gravitasi, sehingga mampu meningkatkan aliran balik vena ke jantung dan mencegah pula timbulnya statis vena.

Berkolaborasi dengan dokter dalam pemberian injeksi furosemide ini termasuk dalam terapi diuretic yang berguna untuk meningkatkan aliran urin guna mengurangi keadaan oliguria pada klien dan untuk menurunkan status kelebihan cairan. Selain itu, furosemide ini terbukti bermanfaat untuk mencegah sumbatan di tubulus (Morton, 2014). Hal ini didukung pula oleh Butcher \& Liu (2012), yang menyatakan bahwa diuretic ini memiliki manfaat untuk meningkatkan output urin sehingga mampu membantu meminimalkan keseimbangan cairan pada klien. Sedangkan, kolaborasi terapi injeksi ketorolac pada pasien gagal ginjal kronik digunakan untuk mengurangi nyeri pada bagian kandung kemih klien yang mengalami pembesaran. Namun, kolaborasi ini hanya bertahan sehari atau pada saat dilakukan pengkajian awal saja. Hal ini disebabkan, dokter penanggungjawab telah menyadari bahwa pemberian antara furosemide dan ketorolac merupakan tindakan yang kurang tepat. Sehingga, terapi injeksi tersebut dihentikan. Mengenai tindakan tersebut, didukung oleh studi buku Stockley's Drug Interaction dalam Siti Fatimah (2016) menyatakan bahwa terdapat 5 pasangan obat yang berpotensi mengalami terjadinya efek interaksi obat. Salah satunya, Furosemid dengan Ketorolac yang jika diteruskan efek dari ketorolac tersebut akan mempengaruhi akivitas dari furosemide sehingga akan menghasilkan efek yang memungkinan terjadinya penurunan kadar elektrolit tubuh.

Berdasarkan hasil evaluasi selama tindakan implementasi 3 x 24 jam pada diagnosa kelebihan volume cairan berhubungan dengan gangguan mekanisme regulasi didapatkan evaluasi keseluruhan yakni Ny. S mampu mengatasi sebagian dari masalah yang ada pada dirinya. Hal ini diperjelas dengan adanya tabel 1 pada poin hasil evaluasi sebelumnya. Dalam tabel tersebut menghasilkan pembahasan dari beberapa poin perubahan sebagai berikut : Perubahan tekanan darah klien yang mampu menggambarkan adanya ke-efektifan terhadap pemantauan kelebihan volume cairan atau dengan kata lain, pemenuhan kebutuhan cairan dan elektrolit klien dengan gagal ginjal kronik tersebut cukup terpenuhi dengan adanya perubahan tekanan darah yang mendekati nilai normal usianya. Nilai normal tekanan darah klien dalam kelompok usia lansia dalam slideshare Tri Kusniati (2017) yakni berada pada kisaran 130-150/8090mmHg. Penurunan tekanan darah Ny. S selaras dengan penelitian Luluk dkk (2020), yang dimana pada penderita gagal ginjal kronik cenderung memiliki tekanan darah yang tinggi, oleh sebab itu, diharapkan penderita gagal ginjal kronik tersebut dapat melakukan usaha untuk mengurangi tekanan darah seperti mengurangi tingkat stress, mengurasi asupan cairan dan juga meminum obat penurun tensi sesuai dengan anjuran dokter.

Pada tabel $1 \mathrm{Ny}$. S mengalami penurunan hasil perhitungan balance cairan yang cukup baik. Hal ini menggambarkan adanya efektivitas penggunaan table monitoring intake dan output cairan. Namun, pada saat klien mendapatkan terapi hemodialisa, penurunan hasil balance cairannya terbilang sedikit yakni dari (+) $52 \mathrm{cc}$ menjadi (+) $40 \mathrm{cc}$. Hal ini disebabkan oleh rasa haus yang timbul setelah beberapa jam terapi hemodialisa dilakukan. Selain itu, adanya respon spontan pada klien guna menanggapi rasa hausnya yakni menambah asupan cairan dalam bentuk air minum meski dalam beberapa teguk. Berhubungan dengan tindakan tersebut, kebutuhan cairan dan elektrolit $\mathrm{Ny}$. S masih 
dalam rentang terpenuhi dan terkendali, sebab nilai positif pada klien tidak melebihi nilai positif sebelumnya. Hal ini sejalan dengan penelitian Angraini dan Putri (2016), yang menyatakan bahwa pemantauan intake output cairan dan elektrolit pada klien gagal ginjal kronik dengan menggunakan fluid intake output chart, terbukti efektif mengatasi overload cairan pada klien. Hal ini dapat dibuktikan dengan berkurangnya manifestasi overload cairan yang terjadi pada klien tersebut.

Menurunnya frekuensi nafas klien dari yang awalnya 20x/menit dalam rentang normal usia lansia yakni 14-16x/menit menjadi menurun bertahap hingga normal kembali yakni 16x/menit pada hari ketiga di tabel 1 . Hal ini dikarenakan adanya perubahan posisi tidur klien yang semula berbaring terlentang menjadi posisi semifowler (kepala ditinggikan 30 derajat). Berkaitan dengan hal tersebut, klien menjadi lebih mudah menarik serta menghembuskan nafasnya. Kemudian, penurunan frekuensi nadi Ny. S menuju kepada angka normalnya menurut tabel 1 dimana pada kelompok usianya, frekuensi nadi klien berada di rentang 60-70x/menit. Kestabilan BB serta membaiknya hasil laboratorium Ny. S merupakan bukti dari perbaikan manifestasi overload seperti yang dikatakan pada penelitian Anggraini dan Putri (2016), sebelumnya.

\section{SIMPULAN}

Asuhan keperawatan yang telah dilakukan selama 3x24 jam mampu menggambarkan ke-efektifan pemenuhan kebutuhan cairan dan elektrolit pada pasien gagal ginjal kronik yang tengah menjalani hemodialisa rutin dengan diberlakukannya pemantauan cairan, serta manajamen cairan yang baik. Dengan begitu, dapat ditarik kesimpulan bahwa tujuan dari penelitian ini dapat tercapai yang ditandai dengan hasil monitoring yang menggambarkan penurunan manifestasi overload cairan pada klien gagal ginjal kronik dengan kata lain, masalah pada studi kasus tersebut mampu teratasi cukup baik dengan rencana tindak lanjut seperti melanjutkan intervensi terhadap pemantauan cairan klien.

\section{REFERENSI}

Abuelo, J.G. (1999). Large Interdialytic Weight Gain : cause, consequences, and corrective measures. Seminar in dialysis.

Ambarwati, F. R. (2014). Konsep Kebutuhan Dasar Manusia. Yogyakarta : Dua Satria Offset

Angraini, Fany Putri, Arcellia F. (2016). Pemantauan Intake Output Cairan Pada Pasien Gagal Ginjal Kronik Dapat Mencegah Overload Cairan. Jurnal Keperawatan Indonesia : 152-160

Ariani S. (2016). Stop! Gagal Ginjal. Yogyakarta : Istana Medika

Alimul H, A. Aziz. 2008. Pengantar Kebutuhan Dasar Manusia Aplikasi Konsep 61 dan Proses Keperawatan. Jakarta: Salemba Medika.

Apriyaningsih, T. (2016). Asuhan Keperawatan pemenuhan kebutuhan cairan dan elektrolit dengan Gagal Ginjal Kronik. 1. Diakses melalui elib.stikesmohgombong.ac.id

Bare \& Smeltzer. (2002). Buku Ajar Keperawatan Medikal Bedah. Brunner \& 
Jendela Nursing Journal, 5(1), 2021,

Suddart (Alih bahasa Agung Waluyo). Edisi 8. Volume 3. Jakarta:EGC

Baxter, Editor. (2008). Stockley's Drug Interactions. Eight Edition. London : Pharmaceutical Press.

Black, J. M. \& Hawks, J. H. (2009). Medical- surgical nursing: Clinical management for positive outcomes ( ${ }^{8 t h}$ Ed.). St. Louis: Saunders Elsevier.

Butcher,B.W., \& Liu,K.D. (2012). Fluid overload in AKI-F.piphenomonen or Putative Effect on Mortality. Curr Opin Crit Care. Author manuscript; araible in PMC.

Cianci, et al. (2009). Hypertension in hemodialysis. An Overview on Physiopathology and Therapeutic Approach in Adults and Childrens. The Open Urology \& Nephrology Journal.

Dongoes, M.E., Moorhouse, M.F., \& Murr, A.C. (2010). Nursing care plans:guideline for individualizing client care across the life span ( ${ }^{8 t h} E d$.). Philadelphia: F. A Davis Company.

Faruq, M.H. (2017). Upaya Penurunan Volume Cairan pada Pasien Gagal Ginjal Kronik. Diakses dari eprints.ums.ac.id pada tanggal 19 Desember 2020

Fisher, L. (2006). Psychological Intervention in Fluid Management. Diakses di http://proquest.umi.com/pqdweb?index $=16 \&$ did $=1456931461 \&$ Srchmode $=1 \&$ sid $=7 \&$ Fmt $=6 \&$ VInst=PROD $\&$ VType $=P Q D \& R Q T=309 \&$ Vname $=P Q D \& T S=12409$ 93656\&clientId $=63928$.

Halim \& Yogyartono. (2012). Pruritus Uremic Pada Penyakit Ginjal Kronik. Majalah Kedokteran FK UKI 2012 Vo. XXVIII No.2.

Kusniati, Tri. (2017). Slideshare Nilai Normal Tanda-Tanda Vital. Diakses pada https://www.slideshare.net/trikusniati/nilai-normal-tanda-tanda-vital 23 Mei 2021.

Lopez-Gomez, J. M (2005). Interdialytic Weight Gain as Marker of Blood Pressure, Nutrition, and Survival in Hemodialysis Patients. International Society of Nephrology. 67 (93), S63-S68.

Luluk, U. Puji, K. Dewi,H, Sri, K \& Widianingsih. (2020). Hubungan Durasi Hemodialisa dengan tekanan darah pasien gagal ginjal kronik di ruang hemodialisa RSI Pati. Indonesia Jurnal Perawat, Vol. 5, No.1.

62

Mansjoer, A. (2000). Kapita Selekta Kedokteran jilid I. Jakarta : Media Aesculapius.

Meilianna, R., \& Wiarsih, W. (2013). Hubungan Kepatuhan Pembatasan Cairan Terhadap Terjadinya Overload pada Pasien Gagal Ginjal Kronik Post Hemodialisa. Diakses dari lib.ui.ac.id pada tanggal 10 Desember 2020.

Morton, P.G. (2014). Keperawatan kritis pendekatan asuhan holistik. Volume 1. Jakarta : EGC. 
Jendela Nursing Journal, 5(1), 2021,

NANDA. (2018). NANDA-I Diagnosis Keperawatan: Definisi dan Klasifikasi 20182020. (T. H. Herdman \& S. Kamitsuru, Eds.) (11th ed.). Jakarta: EGC.

Pace, R.C. (2007). Fluid management in patient on hemodialysis. Nephrplogy Nursing Journal September-October. Vol. 34, No. 5.

PPNI, T. P. (2017). Standar Diagnosis Keperawatan Indonesia (SDKI): Definisi dan Indikator Diagnostik ((cetakan III) ${ }^{1 \text { st }}$ ed.). Jakarta: DPP.

PPNI. PPNI, T. P. (2018). Standar Intervensi Keperawatan Indonesia (SIKI): Definisi dan Tindakan Keperawatan ((cetakan II) ${ }^{1 \text { st }}$ ed.). Jakarta: DPP.

PPNI. PPNI, T. P. (2019). Standar Luaran Keperawatan Indonesia (SLKI): Definisi dan Kreteria Hasil Keperawatan ((cetakan II) ${ }^{1 \text { st }}$ ed.). Jakarta: DPP PPNI.

Priska, N. \& Herlina,S. (2019). Efikasi Diri Pembatasan Cairan Terhadap Intradialytic Weight Gain Pasien Gagal Ginjal Kronik Di Ruang Hemodialisa RSUD Pasar Minggu. Jurnal Ilmiah Ilmu Keperawatan Indonesia. Volume 09. 601-608.

Rustiawati, E. (2012). Dietary Intake Monitoring Application ( DIMA) Untuk Evaluasi Asupan Cairan Dan Diet Bagi Pasien Hemodialisa.

Sapri, A (2004). Faktor-faktor yang mempengaruhi kepatuhan dalam mengurangi asupan cairan pada penderita gagal ginjal kronik yang menjalani hemodialisis di RSUP Dr. H. Abdul Moelek Bandar Lampung. http://indonesianursing.com/2008

Satria E.N dan Dessy R.H. (2016). Hubungan Lama Menjalani Hemodialisis dengan Frekuensi Pernafasan pada Pasien Gagal Ginjal. Diakses melalui http://ojs.unikkediri.ac.id/index.php/nsj/article/view/832/772

Sari, L.R. (2016). Upaya mencegah kelebihan volume cairan pada pasien chronic kidney disease. 4. Diakses dari http://jurnal.usu.ac.id

Setyaningrum, S. (2016). Pemberian posisi kaki ditinggikan 30 derajat diatas tempat tidur terhadap penurunan edema kaki. 17. Diakses dari digilib.stikeskusumahusada.ac.id

Sharaf, A. Y. (2016). The Impact of Educational Interventions on Hemodialysis patient's Adherence to Fluid and Sodium Restriction. IOSR Journal of Nu 63 and Health Science (IOSR-JNHS). 2016; 50 - 60.

Siti, F. (2016). Studi Potensi Interaksi obat pada terapi pasien Penyakit Ginjal Kronis $(P G K)$ di Instalasi rawat inap RSUD Jombang. Diakses melalui http://etheses.uinmalang.ac.id/13492/1/13670058.pdf 
Jendela Nursing Journal, 5(1), 2021,

Sitanggang, Sartika (2009). Pengaruh Terapi Perilaku Kgonitif terhadap pembatasan asupan cairan pasien hemodialisa di RSUP H. Adam malik Medan. Diakses di http://repository.usu.ac.id/handle/123456789/1668?mode=full\&submit_simple $=S$ how+full+item+record.

Smeltzer, S.C, Bare, B.G, Hinkle, J.L., Cheever. K.H. (2010). Brunner \& Suddarth's Texbook of Medical Surgical Nursing. Philadelphia : Lipincott William \& Wilkins.

Sullivan, D., McCarthy,G. (2009). Exploring the symptom of fatigue in patients with end stage renal disease. Neprhology Nursing Journal.

Suryarinilsih, Yosi. (2010). Hubungan penambahan berat badan antara dua waktu dialisis dengan kualitas hidup pasien hemodialisis di rumah sakit Dr. M. Djamil Padang. Universitas Indonesia. 